\title{
Sex can affect participation, engagement, and adherence in trials
}

\author{
Alison Avenell clinical chair in health services research ${ }^{1}$, Clare Robertson research fellow ${ }^{1}$, Fiona \\ Stewart research fellow ${ }^{1}$, Dwayne Boyers research fellow ${ }^{2}$, Flora Douglas lecturer in public health ${ }^{3}$, \\ Daryll Archibald research fellow ${ }^{4}$, Edwin van Teijlingen professor of reproductive health research ${ }^{5}$, \\ Pat Hoddinott chair in primary care ${ }^{6}$, Charles Boachie statistician ${ }^{7}$
}

\begin{abstract}
${ }^{1}$ Health Services Research Unit, School of Medicine, Medical Sciences and Nutrition, University of Aberdeen, Foresterhill, Aberdeen AB25 2ZD, UK; ${ }^{2}$ Health Services Research Unit and Health Economics Research Unit, School of Medicine, Medical Sciences and Nutrition, University of Aberdeen, Foresterhill, Aberdeen AB25 2ZD, UK; ${ }^{3}$ Rowett Institute of Nutrition and Health, School of Medicine, Medical Science and Nutrition, University of Aberdeen, Foresterhill, Aberdeen AB25 2ZD, UK; ${ }^{4}$ Scottish Collaboration for Public Health Research and Policy (SCPHRP), Centre for Population Health Sciences (CPHS), University of Edinburgh, Edinburgh EH8 9DX, UK; ${ }^{5}$ Centre for Midwifery, Maternal and Perinatal Health, Faculty of Health and Social Sciences, Bournemouth House, Bournemouth University, Bournemouth BU1 3LH, UK; ${ }^{6}$ NMAHP Research Unit, Unit 13, Scion House, Stirling University Innovation Park, Stirling FK9 4NF, UK; ${ }^{7}$ Institute of Cardiovascular and Medical Sciences, University of Glasgow, Glasgow G12 9QQ, UK
\end{abstract}

We enjoyed Wallach and colleagues' analysis of sex based subgroup differences in randomised controlled trials in the Cochrane Library. ${ }^{1}$ The authors found little evidence for clinically relevant sex-treatment interactions for outcomes. Not apparent in their analysis are the social, psychological, and contextual factors that can influence men's and women's participation, engagement, and adherence to health interventions, services, and trial procedures, particularly for programmes to change health related behaviours. For example, men are much less likely than women to take part in trials of weight loss programmes for obesity management. ${ }^{23}$

To examine the reasons for this, and to help develop interventions that are more likely to engage men to participate in and continue with weight loss programmes, we undertook a mixed methods systematic review of qualitative and quantitative evidence (including randomised controlled trials) of weight management for men who were obese. ${ }^{2}$ This led to new guidance endorsed by Public Health England on weight management for men. ${ }^{4}$

We performed a pre-specified analysis of dropouts from trials by sex, where individual trials presented data separately for men and women. This showed that, although men were less likely to participate in weight loss trials, they were more likely to complete the trial than women, with an absolute difference of $11 \%$ (95\% confidence interval $8 \%$ to $14 \%) .{ }^{5}$ Sex, and gender, can affect the way we behave, our motivations, our perceptions of the world around us and ourselves, and our reasons for changing (or not) our behaviours.

\section{Competing interests: None declared.}

Wallach JD, Sullivan PG, Trepanowski JF, Steyerberg EW, loannidis JPA. Sex based subgroup differences in randomized controlled trials: empirical evidence from Cochrane meta-analyses. BMJ 2016;355:i5826. doi:10.1136/bmj.i5826 pmid:27884869.

2 Robertson C, Archibald D, Avenell A, et al. Systematic reviews of and integrated report on the quantitative, qualitative and economic evidence base for the management of obesity in men. Health Technol Assess 2014;18:v-vi, xxiii-xxix, 1-424. doi:10.3310/hta18350 pmid: 24857516 .

3 Pagoto SL, Schneider KL, Oleski JL, Luciani JM, Bodenlos JS, Whited MC. Male inclusion in randomized controlled trials of lifestyle weight loss interventions. Obesity (Silver Spring) 2012;20:1234-9. doi:10.1038/oby.2011.140 pmid:21633403.

$4 \quad$ Men's Health Forum and Public Health England. How to make weight loss services work for men. https://www.menshealthforum.org.uk/sites/default/files/pdf/how to weight final Ir 1 .pdf

5 Robertson C, Avenell A, Boachie C, et al. Should weight loss and maintenance programmes be designed differently for men? A systematic review of long-term randomised controlled trials presenting data for men and women: The ROMEO project. Obes Res Clin Pract 2016;10:70-84. doi:10.1016/j.orcp.2015.04.005 pmid:25937165.

Published by the BMJ Publishing Group Limited. For permission to use (where not already granted under a licence) please go to http://group.bmj.com/group/rights-licensing/ permissions 